\title{
Selection of Beef Quality Factors Represented by Time-Temperature Integrator (TTI)
}

\author{
Eunji Kim ${ }^{1,4}$, Keehyuk Kim²,4, Seung Won Jung ${ }^{1,4}$, Ku-Young Chung ${ }^{3}$, and Seung Ju Lee ${ }^{1,4 *}$ \\ ${ }^{1}$ Department of Food Science and Biotechnology, Dongguk University-Seoul, Seoul 100-715, Korea \\ ${ }^{2}$ Department of Culinary Nutrition, Woosong University, Daejeon 300-718, Korea \\ ${ }^{3}$ Department of Animal Resources Scinence, Sangji University, Wonju 220-702, Korea \\ ${ }^{4}$ Center for Intelligent Agro-Food Packaging (CIFP), Dongguk University, Seoul 100-715, Korea
}

\begin{abstract}
Beef qualities which can be properly predicted by time-temperature integrator (TTI), a chromatic indicator, were selected in terms of its similarity of temperature dependence between beef qualities and TTI, denoted by Arrhenius activation energy $\left(E_{a}\right)$. The high similarity is required to afford accurate prediction. A devised enzymatic TTI based on laccase (an oxidase), which catalyses the oxidation on 2,2'-azino-bis-(3-ethylbenzothiazoline-6-sulphonic acid) producing color development, was applied. The factors of beef quality, such as volatile basic nitrogen (VBN), pH, color (CIE L*, a*), Warner-Bratzler shear force (WBSF), Pseudomonas spp. count, and lactic acid bacteria (LAB) count were considered for the selection. $E_{a}$ $(55.48 \mathrm{~kJ} / \mathrm{mol})$ of the TTI was found to be similar to those of the beef qualities (all referred) in the order of LAB count (53.54 kJ/mol), CIE a* value (61.86 kJ/mol), pH (65.51 kJ/mol), Pseudomonas spp. Count (44.54 kJ/mol), VBN (67.98 kJ/ $\mathrm{mol})$, WBSF $(40.67 \mathrm{~kJ} / \mathrm{mol})$, and CIE L* value $(33.72 \mathrm{~kJ} / \mathrm{mol})$. The beef qualities with more similar $E_{a}$ to that of the TTI showed less difference between real and TTI predicted levels. In conclusion, it was found out that when applying TTI to food packages, their $E_{a}$ similarity should be checked to assure accurate estimation of food quality levels from TTI response.
\end{abstract}

Key words: beef quality, TTI (time-temperature integrator), laccase, kinetics, temperature dependence

\section{Introduction}

As consumers' demand and interests on high quality foods increase, beef products also need to improve their qualities and the conditions of processing, distribution and storage for food safety (Byeon et al., 2009). Beef qualities are evaluated by off-line or on-line measurements. There are various off-line measurements such as physical, chemical and biological tests that are usually practiced in the laboratories, but are not available to consumers. Recently, on-line measurement is being focused on intelligent food packaging. An intelligent label on the package represents the inner food qualities by displaying its color change during storage (Han et al., 2011). There are several kinds of intelligent labels available, but the only intelligent label in practical use is time-temperature integrator (TTI).

\footnotetext{
*Corresponding author: Seung Ju Lee, Department of Food Science and Biotechnology, Dongguk University-Seoul, Seoul 100-715, Korea. Tel: 82-2-2260-3372, Fax: 82-2-2260-3372, E-mail: Lseungju@dongguk.edu
}

Time-temperature integrator is an intelligent packaging indicator that can predict the quality of foods in packaging by color change (Han et al., 2011). Thus, color, intensity and clear color response of TTI according to a history of time-temperature are important factors in displyaing TTI color change. Currently, there are several kinds of TTIs available including enzymatic, microbiological, diffusion, polymer, or photochemical types. One of the longest used commercial TTIs is enzymatic TTI with the typical use of lipase. This lipase-based TTI shows $\mathrm{pH}$ dependent color change due to the enzymatic hydrolysis of a lipid substrate (Agerhem and Nilsson, 1981; Blixt et al., 1977; Bobelyn et al., 2006). Laccase is a highly efficient dye or pigment decolorizing enzyme (Kunamneni et al., 2008; Moshtaghioun et al., 2011) which was used to devise this enzymatic TTI.

Beef quality changes during storage, processing, or distribution have been investigated by many researchers (Han and Lee, 2011; Montgomery et al., 2003; Sallam and Samejima, 2004; Zakrys et al., 2008; Zhang et al., 2011). Beef qualities were considered under a number of factors, namely chemical factors $(\mathrm{pH}, \mathrm{TBARS}, \mathrm{VBN}$, 
oxymyoglobin), physical factors (Warner-Bratzler shear force, water holding capacity), biological factors (total colony number, Pseudomonas spp., Enterobacteriaceae, Brochothrix thermosphacta, lactic acid bacteria), and sensory factors (flavor, appearance, texture, degree of decay, overall preferences). The primary environmental factor influencing beef quality is time-temperature history during storage (Thomas et al., 2007). The quality alters with storage temperature, and the accumulated quality changes are determined by storage time. Under dynamic temperature conditions, the rate of the quality loss increases with higher temperature dependence, and vice versa. This indicates that quality with the same temperature dependence is influenced to the same degree when the temperature fluctuates. The temperature dependence is usually denoted by Arrhenius activation energy $\left(E_{a}\right)$ (Taoukis, 2001). Enzymatic TTI is also a system with organic substances in which the color development reaction is influenced by time-temperature history. Therefore, beef quality representing TTI color change should have the same temperature dependence as that of TTI. It was reported that the allowable difference in $E_{a}$ between TTI and the accompanied food should be within $\pm 25 \mathrm{~kJ} / \mathrm{mol}$ (Taoukis, 2001).

In this study, $E_{a}$ for temperature dependence of beef qualities and TTI color changes were analyzed and compared to select beef quality which could be best represented by TTI. The beef qualities and their $E_{a}$ considered here were all referred from our previous work (Byeon et al., 2009). An enzymatic TTI in use was devised based on laccase (an oxidase). The beef quality represented by TTI was selected in terms of temperature dependence similarity.

\section{Materials and Methods}

\section{Materials}

A laccase chemical modification was carried out to increase enzyme stability during storage (López-Cruz et al., 2006). A mixture of laccase at a given $\mathrm{M}$ and 50-fold $\mathrm{M}$ of monomethoxypolyethylene glycol was prepared in a solution of borate buffer ( $\mathrm{pH} 10.0)$. It was kept for $2.5 \mathrm{~h}$ at $25^{\circ} \mathrm{C}$ in water bath. Following this, 50 -fold volume of $100 \mathrm{mM}$ sodium acetate buffer with a $\mathrm{pH}$ of 5.0 was added.

Laccase (EC 1.10.3.2, Sigma Co., USA) was prepared in a solution of $100 \mathrm{mM}$ sodium acetate buffer with a $\mathrm{pH}$ of 5.0. ABTS (substrate for laccase, 2,2'-azino-bis-(3-ethylbenzothiazoline-6-sulphonic acid)), glycerol, and bovine serum albumin (enzyme stabilizer).

\section{Laccase activity assay}

The standard assay conditions were as follows. Light absorption at $430 \mathrm{~nm}$ occurs quantitatively as ABTS (2,2'-azino-bis-(3-ethylbenzothiazoline-6-sulphonic acid)) is oxidized by the enzyme; therefore, the enzyme activity was determined based on the absorbance at $430 \mathrm{~nm}$ at $30^{\circ} \mathrm{C}$ (Kunamneni et al, 2008). The standard assay solution was composed of $0.5 \mathrm{mM}$ ABTS in $100 \mathrm{mM}$ sodium acetate buffer ( $\mathrm{pH} 5.0)$. A total of $3 \mathrm{~mL}$ of the reaction mixture was pre-equilibrated at $30^{\circ} \mathrm{C}$, after which $20 \mu \mathrm{L}$ of the enzyme solution was added, and the oxidation of ABTS was measured based on the increase in absorbance at $430 \mathrm{~nm}\left(\varepsilon_{430}=36,000 \mathrm{M}^{-1} \mathrm{~cm}^{-1}\right)$. One unit of laccase activity corresponds to the oxidation of $1 \mu \mathrm{mol}$ ABTS per minute under these described conditions.

\section{Preparation of laccase based TTI prototype}

The laccase TTI prototype was composed of two parts enzyme and substrate solutions. The enzyme solution contained 0.00417 unit of the modified enzyme in $8 \%$ chemically modified laccase solution, $1 \%$ of $0.1 \mathrm{mg} / \mathrm{mL}$ bovine serum albumin, $100 \mathrm{mM}$ sodium acetate buffer $(\mathrm{pH}$ 5.03 ) and $45 \%$ glycerol. The substrate solution included $10 \mathrm{mM}$ ABTS, $100 \mathrm{mM}$ sodium acetate buffer (pH 5.0), and $45 \%$ glycerol. The glycerol solution was added to TTI prototype's stability. The TTI prototype was activated by mixing the enzyme solution of $0.5 \mathrm{~mL}$ and the substrate solution of $0.5 \mathrm{~mL}$. TTI responses were expressed in the absorbance value at $430 \mathrm{~nm}$ representing TTI color change.

\section{Determination of the kinetic and Arrhenius para- meters of TTI}

The TTI prototypes were kept at $5^{\circ} \mathrm{C}, 15^{\circ} \mathrm{C}$, and $25^{\circ} \mathrm{C}$ in temperature-controlled incubators (HST-103 PID type temperature controlled incubator, Hanbaek Co., Korea) and were only taken out of the incubators for the absorbance measurements using a $1 \mathrm{~mm}$ quarts-cuvetts cell.

According to the TTI kinetics characterized by Taoukis and Labuza (1989), the color response of TTIs were expressed as follows:

$$
\mathrm{Y}=k \mathrm{t}
$$

where $\mathrm{Y}$ is the color response value in absorbance, $k$ is the reaction rate constant, and $\mathrm{t}$ is the reaction time. By plotting a curve of absorbance vs. time, the rate constant was estimated based on the fit of the linear regression.

The activation energy of TTIs was presented by taking natural logarithm on both sides of the Arrhenius function 
(Wanihsuksombat et al., 2010; Yan et al., 2008):

$$
\ln k=\frac{E_{a}}{R T}+\ln A
$$

where $E_{a}$ is the activation energy, $T$ is the temperature, $R$ is the gas constant, and $A$ is the pre-exponential factor. By plotting a curve between $\ln k$ and $1 / T$, the slope $\left(E_{d} / R\right)$ and the intercept $(\ln A)$ were estimated by the fit of the linear regression.

\section{Kinetic and Arrhenius parameters for beef qualities}

The authors had already published a paper regarding beef quality changes during storage, kinetic equations at different temperatures and Arrhenius parameters (Byeon et al., 2009). The relevant data were cited as shown in Table 1 .

\section{Statistical analysis}

The kinetic and Arrhenius parameters for TTI were obtained by determining the slope of Eqs. (1) and (2),

Table 1. The kinetic equations at different temperatures and Arrhenius parameters for beef quality factors (referred from Byeon et al., 2009)

\begin{tabular}{|c|c|c|c|}
\hline $\begin{array}{c}\text { Beef quality } \\
\text { variables }\end{array}$ & $\begin{array}{l}\text { Temper- } \\
\text { ature }\left({ }^{\circ} \mathrm{C}\right)\end{array}$ & Kinetic equations ${ }^{1)}$ & $\begin{array}{c}E_{a} \\
(\mathrm{~kJ} / \mathrm{mol})\end{array}$ \\
\hline \multirow{3}{*}{$\begin{array}{c}\text { Pseudomonas } \\
\text { spp. count } \\
(\mathrm{Log} \text { CFU/g) }\end{array}$} & 5 & $\log y=3.76+2.30 \times 10^{-2} t$ & \multirow{3}{*}{44.54} \\
\hline & 15 & $\log y=3.76+4.69 \times 10^{-2} t$ & \\
\hline & 25 & $\log y=3.76+8.38 \times 10^{-2} t$ & \\
\hline \multirow{3}{*}{$\begin{array}{l}\text { LAB count } \\
(\mathrm{Log} C F U / g)\end{array}$} & 5 & $\log y=2.52+1.65 \times 10^{-2} t$ & \multirow{3}{*}{53.54} \\
\hline & 15 & $\log y=2.52+5.43 \times 10^{-2} t$ & \\
\hline & 25 & $\log y=2.52+1.15 \times 10^{-1} t$ & \\
\hline \multirow{3}{*}{$\begin{array}{c}\mathrm{VBN} \\
(\mathrm{mg} \%)\end{array}$} & 5 & $\mathrm{y}=5.76+7.40 \times 10^{-2} \mathrm{t}$ & \multirow{3}{*}{67.98} \\
\hline & 15 & $y=5.76+2.52 \times 10^{-1} t$ & \\
\hline & 25 & $\mathrm{y}=5.76+5.30 \times 10^{-1} \mathrm{t}$ & \\
\hline \multirow{3}{*}{$\mathrm{L}^{*}$ value } & 5 & $\mathrm{y}=45.41-2.80 \times 10^{-2} \mathrm{t}$ & \multirow{3}{*}{33.72} \\
\hline & 15 & $\mathrm{y}=45.41-6.40 \times 10^{-2} \mathrm{t}$ & \\
\hline & 25 & $\mathrm{y}=45.41-7.40 \times 10^{-2} \mathrm{t}$ & \\
\hline \multirow{3}{*}{$a^{*}$ value } & 5 & $\mathrm{y}=18.54-2.10 \times 10^{-2} \mathrm{t}$ & \multirow{3}{*}{61.86} \\
\hline & 15 & $y=18.54-9.10 \times 10^{-2} t$ & \\
\hline & 25 & $\mathrm{y}=18.54-1.25 \times 10^{-1} \mathrm{t}$ & \\
\hline \multirow{3}{*}{$\mathrm{pH}$} & 5 & $\ln y=1.71+6.00 \times 10^{-5} \mathrm{t}$ & \multirow{3}{*}{65.51} \\
\hline & 15 & $\ln y=1.71+2.00 \times 10^{-4} t$ & \\
\hline & 25 & $\ln y=1.71+1.00 \times 10^{-4} t$ & \\
\hline \multirow{3}{*}{$\begin{array}{c}\text { WBSF } \\
\text { (g-force) }\end{array}$} & 5 & $\mathrm{y}=649.85+1.349 \mathrm{t}$ & \multirow{3}{*}{40.67} \\
\hline & 15 & $y=649.85+2.438 t$ & \\
\hline & 25 & $\mathrm{y}=649.85+4.396 \mathrm{t}$ & \\
\hline
\end{tabular}

${ }^{1)} \mathrm{y}$ and $\mathrm{t}$ represent beef quality variables and time $(\mathrm{h})$, respectively. Those containing $\log \mathrm{y}$ and $\mathrm{y}$ indicate first-order reaction and zero-order reaction, respectively. The intercepts are pseudo intercepts obtained from the linear regression, not indicating the initial levels of beef quality variables. using the trendline feature of Microsoft Excel.

To see an agreement of the curves between different temperatures (Fig. 3), the data dispersion was analyzed in terms of coefficient of variation (CV). Before the analysis, the data were converted to coded values (0-1) in order to remove some unfairness from the different units and magnitudes of the quality variables. The maximum (coded 1) and minimum (coded 0) quality values were set up in a particular range of TTI color index, which was determined to be $0.05-0.40$, reflecting actual food qualities. Microsoft Excel was used in this analysis.

\section{Results and Discussion}

\section{Kinetic and Arrhenius parameters of the laccase based TTI prototype}

Laccase could oxidize ABTS in a very simple reaction mixture composed of only sodium acetate, molecular oxygen, and a trace amount of bovine serum albumin generally used for the enzyme stabilizer. The oxidation caused a change in the color of the reaction mixture from colorless to blue, resulting in absorption of light at a wavelength of $430 \mathrm{~nm}$ (Solís-oba et al., 2008).

Eq. (1) was applied to fit the color responses (absorbance at $430 \mathrm{~nm}$ ) collected from three TTIs during storage at different temperatures. Fig. 1 and Table 2 show that the color responses are linear with high $\mathrm{R}^{2}>0.99$.

To estimate Arrhenius activation energy $\left(E_{a}\right)$, ln $k$ values were plotted against $1 / \mathrm{T}$ (Fig. 2). The $E_{a}$ value of the TTI was found to be $55.48 \mathrm{~kJ} / \mathrm{mol}$ (Table 2). $E_{a}$ of this laccase based TTI prototype was similar to a commercial enzymatic TTI named type C2-15d (Vitsab AB, Sweden) with $50.2 \mathrm{~kJ} / \mathrm{mol}$ (Bobelyn et al., 2006) and a diffusion based TTI with 33-50 kJ/mol (Poças et al., 2008). Using

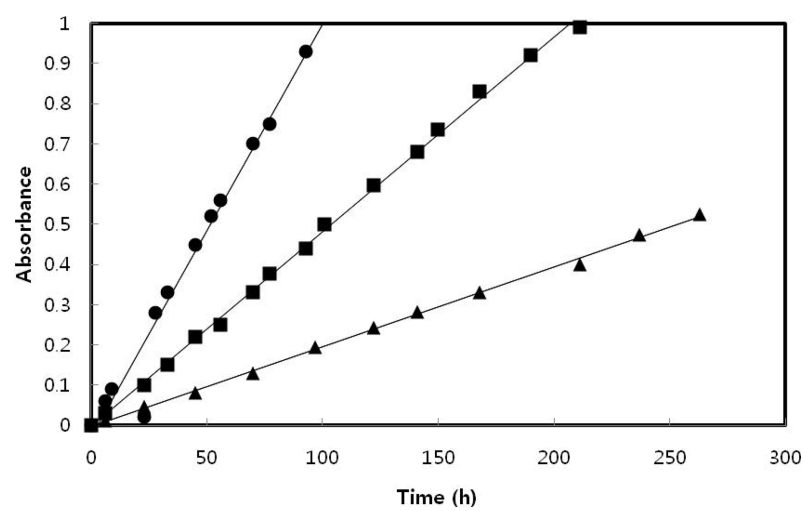

Fig. 1. The plot of TTI color responses (absorbance at 430 nm) vs time at different temperatures. $\triangle, 5^{\circ} \mathrm{C} ; \square, 15^{\circ} \mathrm{C}$; - $25^{\circ} \mathrm{C}$. 
Table 2. The kinetic equations at different temperatures and Arrhenius parameters for TTI color (absorbance at $430 \mathrm{~nm}$ ) changes

\begin{tabular}{ccccc}
\hline \hline $\begin{array}{c}\text { Temperature } \\
\left({ }^{\circ} \mathrm{C}\right)\end{array}$ & $\begin{array}{c}\text { Kinetic } \\
\text { equations }{ }^{1)}\end{array}$ & $\mathrm{R}^{2}$ & $E_{a}(\mathrm{~kJ} / \mathrm{mol})$ & $\mathrm{R}^{2}$ \\
\hline 5 & $\mathrm{y}=2.00 \times 10^{-3} \mathrm{t}$ & 0.9986 & & \\
15 & $\mathrm{y}=4.90 \times 10^{-3} \mathrm{t}$ & 0.9985 & 55.48 & 0.9979 \\
25 & $\mathrm{y}=1.00 \times 10^{-2} \mathrm{t}$ & 0.9807 & & \\
\hline
\end{tabular}

${ }^{1)} \mathrm{y}$ and $\mathrm{t}$ represent TTI color and time (h), respectively.

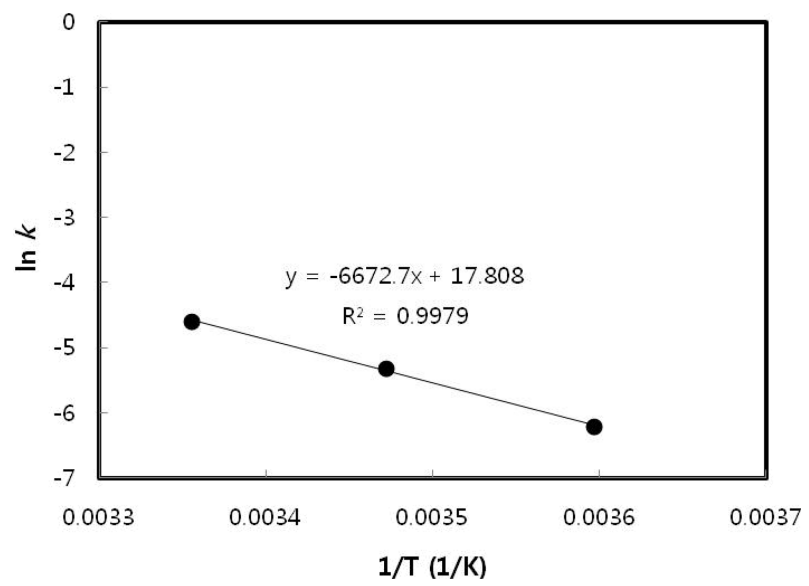

Fig. 2. The logarithmic plot of TTI color response (absorbance at $430 \mathrm{~nm})$ rates $(\ln k)$ vs. inverse of different temperatures $(1 / T)$.

a prototype TTI, this study attempted to select the most appropriate quality factor of beef that can be predicted by TTI.

The similarity of $E_{a}$ between TTIs and the accompanied foods should be ensured because the principle of the food quality prediction from TTI color changes is based on the temperature dependence. If the temperature dependence of both TTIs and the foods is different, the time-temperature history experienced by TTIs cannot be assumed the same as that of the accompanied foods. An allowable difference in the activation energy between the TTIs and the foods must be within $\pm 25 \mathrm{~kJ} / \mathrm{mol}$ to predict food quality (Taoukis, 2001). $E_{a}$ s were found to vary with the variety of foods. The $E_{a} \mathrm{~s}$ of $L$. sakei growth of a microbial TTI and $\mathrm{LAB}$ growth of the accompanied minced beef were $111.90 \mathrm{~kJ} / \mathrm{mol}$ and $106.90 \mathrm{~kJ} / \mathrm{mol}$, respectively (Vaikousi et al., 2009). Meanwhile, even the same foods have different $E_{a}$ s for their quality factors. Byeon et al. (2009) reported that each of the quality factors for beef such as volatile basic nitrogen $(\mathrm{VBN}), \mathrm{pH}$, color $\left(\mathrm{CIE} \mathrm{L*}, \mathrm{a}^{*}\right.$, $\mathrm{b}^{*}$ ), Warner-Bratzler shear force (WBSF), Pseudomonas spp. count, and lactic acid bacteria (LAB) count had different $E_{a}$ s. Meanwhile, b* values had poor $\mathrm{R}^{2}(p<0.90)$, and therefore were excluded from the comparisons with TTI (Table 1 and Fig. 3).

\section{Selection of beef quality factors corresponding to TTI color}

TTI color should be able to represent the accompanied food qualities. The TTI performance could be evaluated by making a storage test. If the same food quality levels are always obtained at a fixed TTI color response, even for the different time-temperature courses, TTIs are said to have high accuracy. Also, the comparison of TTI and food activation energies could be used to evaluate the performance. The authors had reported the $E_{a} \mathrm{~s}$ for beef quality factors as shown in Table 1 . The $E_{a}$ of the laccase enzymatic TTI was found to be closer to those of LAB, CIE a* value, $\mathrm{pH}$, Pseudomonas spp., VBN, WBSF, and CIE L* value in decreasing order. The TTI color responses and the beef quality levels with respect to the storage times were estimated by the relevant mathematical equations shown in Tables 1 and 2. From those estimates, their relationships were depicted as shown in Fig. 3 in which the data on the graphs were just estimates rather than experimental data. The trends in estimates were more easily observed in the relationship rather than those in discrete data. In general, in the beginning of TTI color changes, the trend curves of food qualities vs. TTI color coincided for the different storage temperatures. However, they diverged with increasing TTI color response. If TTI color response levels were different even at the same food quality levels, which were from the higher divergence, TTI should be an indicator with poor accuracy. This also implies that the higher divergence leads to more difference between real and TTI predicted levels of food qualities.

The divergence was statistically analyzed by coefficients of variation (CV). First, an individual CV was calculated on the three data of food quality from three temperatures at a TTI color response. To see an overall dispersion over the TTI color response, 0.05-0.40 abs; the 36 data sets of food quality were extracted at intervals of $0.01 \mathrm{abs}$ from the curves, and then their CVs were averaged. In Table 3, the divergence the averaged CV between the temperatures was the lowest for $\mathrm{pH}$, followed by $\mathrm{LAB}$ count, VBN, Pseudomonas spp. count, CIE a* value, WBSF, and CIE L* value. This indicates that the quality levels of the factors with lower CV would be predicted with higher accuracy for different time-temperature histories. From the similarity of $E_{a}$, on the other hand, the compatibilities with TTI color were found to be higher in LAB count, CIE a* value, $\mathrm{pH}$, Pseudomonas spp. count, 


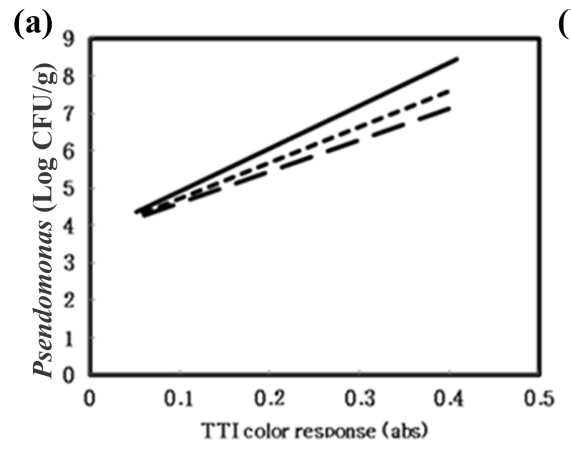

(d)
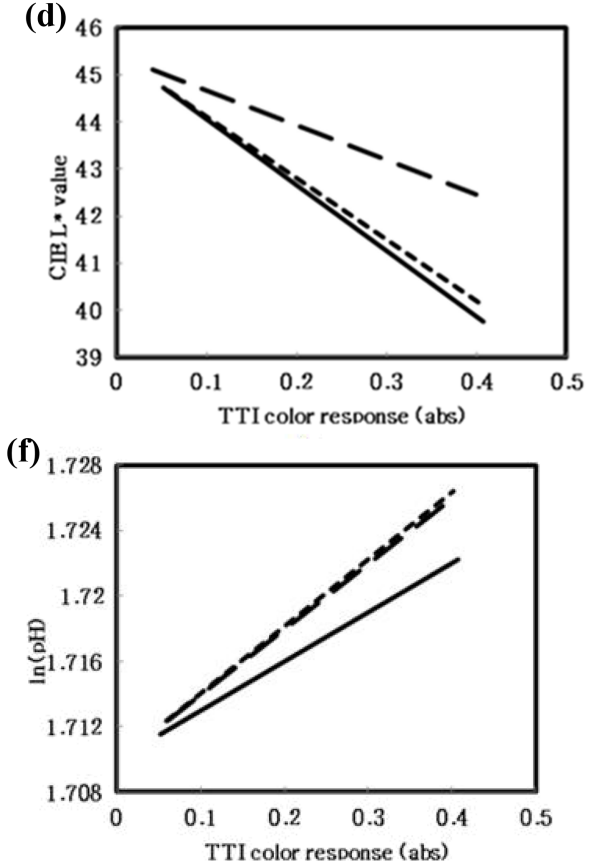
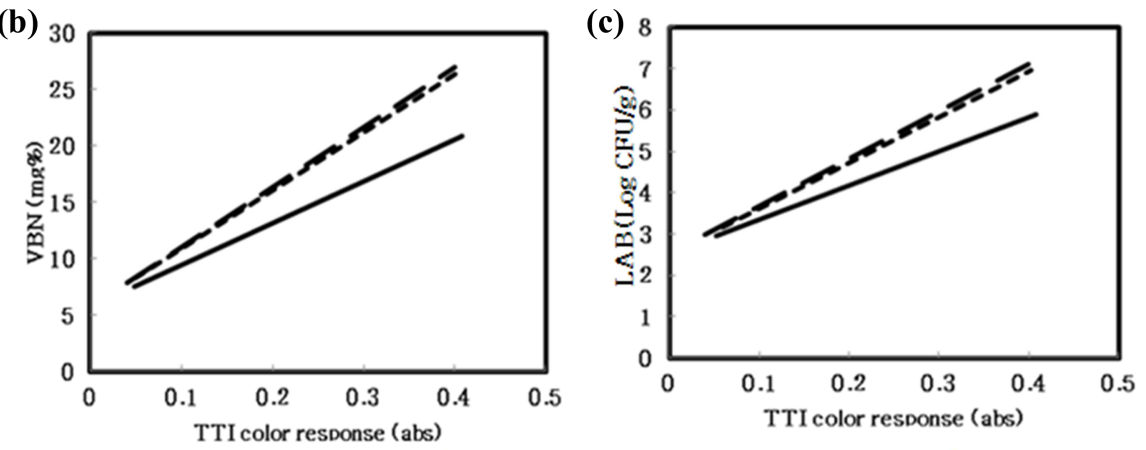

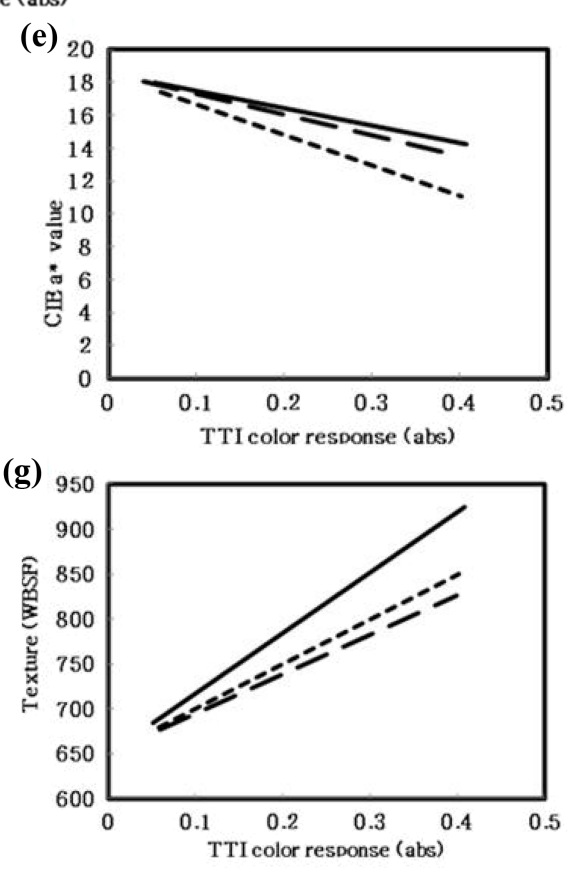

Fig. 3. The relationships between the sets of TTI color responses and beef quality levels during storage. (a) Pseudomonas spp., (b) $\mathrm{LAB},(\mathrm{c}) \mathrm{VBN},(\mathrm{d}) \mathrm{CIE} \mathrm{L}^{*}$ value, (e) $\mathrm{CIE}$ a* value, (f) $\ln (\mathrm{pH})$, (g) WBSF. -, $5^{\circ} \mathrm{C} ; \cdots \cdots, 15^{\circ} \mathrm{C} ;----, 25^{\circ} \mathrm{C}$.

Table 3. Max and min for the coded data and their dispersion shown in Fig. 3

\begin{tabular}{lrcccccc}
\hline \hline & VBN & Pseudomonas spp. & LAB & CIE L* $^{*}$ & CIE a* $^{*}$ & $\ln (\mathrm{pH})^{1)}$ & WBSF \\
\hline $\mathrm{Max}^{2)}(\operatorname{coded}$ 1) & 26.96 & 4.08 & 2.90 & 39.87 & 11.11 & 1.71 & 671.83 \\
Min $(\operatorname{coded}$ ) & 7.61 & 8.36 & 6.99 & 45.04 & 18.02 & 1.73 & 919.65 \\
Averaged CV $(\%)^{3)}$ & 26.98 & 27.08 & 24.57 & 39.69 & 29.32 & 24.16 & 34.00 \\
\hline
\end{tabular}

${ }^{1)} \mathrm{pH}$ changes were in the first order reaction, and the logarithmic $\mathrm{pH}$ was used.

${ }^{2)} \mathrm{Max}$ and min values are the limits of qualities within the range of TTI color response, 0.05-0.40.

${ }^{3)} \mathrm{CV}$ (coefficients of variation) of the coded data $(\mathrm{n}=3)$ from three different temperatures over the TTI color response of $0.05-0.40$. The CVs obtained at every 0.01 interval of TTI color response were averaged.

VBN, WBSF, and CIE $L^{*}$ value in descending order. Although the orders in the divergence and in the similarity were not exactly coincident, the trends suggesting which factors could be more meaningfully predicted could be founded.

\section{Conclusions}

To examine the performance of a prototype TTI based on laccase to predict beef qualities, their temperature dependences were quantitatively analyzed. First, the changes of beef qualities and the TTI color response were kinetically modeled and their relationships were mathematically estimated. After this, the consistencies in the relationships for the different time-temperature histories were examined. The laccase TTI showed consistent relationships with some selected beef quality factors. The only selected qualities would be able to be accurately in- 
dicated by the TTI color changes. Therefore, the process to find the quality factors compatible to TTI is absolutely necessary to use TTI properly.

\section{Acknowledgement}

This study was conducted as a research project of the Center for Intelligent Agro-Food Packaging, Agricultural Research Center (ARC, 710003-03-1-SB110) supported by the Ministry for Food, Agriculture, Forestry and Fisheries of Korea.

\section{References}

1. Agerhem, H. and Nilsson, H. J. (1981) Substrate composition and use thereof. US patent 4,284,719.

2. Blixt, K. G., Juhlin, R., Salenstedt, K. R., Tiru, M., and Tornmarck, S. I. A. (1977) Enzymatic substrate composition adsorbed on a carrier. US patent 4,043,871.

3. Byeon, K. E., An, S. R., Shim, S. D., Lee, J, Y., Hong, K. W., Min, S. G., and Lee, S. J. (2009) Investigation on beef quality indicator of off-flavor development during storage. Korean J. Food Sci. An. 3, 325-333.

4. Bobelyn, E., Hertog, M. L. A. T. M., and Nicolaï, B. M. (2006) Applicability of an enzymatic time temperature integrator as a quality indicator for mushrooms in the distribution chain. Postharvest Bilol. Technol. 42, 104-114.

5. Han, J. Y. and Lee, S. J. (2011) Mathematical modeling of off-flavor development during beef storage. Meat Sci. 88, 712-717.

6. Kunamneni, A., Ghazi, I., Camarero, S., Ballestereos, A. J., Plou, F., and Alcalde, M. (2008) Decolorization of synthetic dyes by laccase immobilized on epoxy-activated carriers. Process Biochem. 43, 169-178.

7. López-Cruz, J. I., Viniegra-González, G., and HernándezArana, A. (2006) Thermostability of native and pegylated Myceliophthora thermophila laccase in aqueous and mixed solvents. Bioconjugate Chem. 17, 1093-1098.

8. Montgomery, J. L., Parrish, F. C., Olson, D. G., Dickson, J. S., and Niebuhr, S. (2003) Storage and packaging effects on sensory and color characteristics of ground beef. Meat Sci. 64, 357-363.

9. Moshtaghioun, S. M., Haghbeen, K., Sahebghadam, A. L., Legge, R., Khoshneviszadeh, R., and Farhadi, S. (2011) Direct spectrophotometric assay of laccase using diazo derivatives of guaiacol. Analytical Chem. 83, 4200-4205.
10. Poças, M. F. F., Delgado, T. F., and Oliveira, F. A. R. (2008) Smart packaging technologies for fruits and vegetables. In: Smart Packaging Technologies. Kerr. J., and Butler. P. (eds). John Wiley and Sons Ltd., West Sussex, England. pp. 151-166.

11. Sallam, K. and Samejima, K. (2004) Microbiological and chemical quality of groud beef treated with sodium lactate and sodium chloride during refrigerated storage. LWT-Food sci. Technol. 37, 865-871.

12. Solís-oba, M., Almendáriz, J., and Viniegra-gonzález, G. (2008) Biotechnological treatment for colorless denim and textile wastewater treatment with laccase and ABTS. Rev. Int. Contam. Ambient. 24, 5-11.

13. Taoukis, P. S. (2001) Modelling the use of time-temperature indicators in distribution and stock rotation. In: Food Process Modelling. Tijskens, L. M. M., Hertog, M. L. A. T. M., Nicola, R. B. M. (eds.) 3rd ed, CRC Press, Washington DC, pp. 402432.

14. Taoukis, P. S. and Labuza, T. P. (1989) Applicability of time temperature indicators as shelf-life monitors of food products. J. Food Sci. 54, 783-788.

15. Thomas, R., Anjaneyulu, A. S. R., Gadekar, Y. P., Pragati, H., and Kondaiah, N. (2007) Effect of comminution temperature on the quality and shelf life of buffalo meat nuggets. Food Chem. 103, 787-794.

16. Vaikousi, H., Biliaderis, C. G., and Koutsoumanis. K. P. (2009) Applicability of a microbial time temperature indicator (TTI) for monitoring spoilage of modified atmosphere packed minced meat. Int. J. Food Microbiol. 133, 272-278.

17. Wanihsuksombat, C., Hongtrakul, V., and Suppakul, P. (2010) Development and characterization of a prototype of a lactic acid-based time-temperature indicator for monitoring food product quality. J. Food Eng. 100, 427-434.

18. Yan, S., Huawei, C., Limin, Z., Fazheng, R., Luda, Z., and Hengtao, Z. (2008). Development and characterization of a new amylase type time-temperature indicator. Food Control 19, 315-319.

19. Zakrys, P. I., Hogan, S. A., O’Sullivan, M. G., Allen, P., and Kerry, J. P. (2008) Effects of oxygen concentration on the sensory evaluation and quality indicators of beef muscle packed under modified atmosphere. Meat Sci. 79, 648-655.

20. Zhang, Y., Mao, Y., Li, K., Dong, P., Liang, R., and Luo, Xin. (2011) Models of Pseudomonas growth kinetics and shelf life in chilled Longissimus dorsi muscles of beef. Asian-Aust. J. Anim. Sci. 24, 713-722.

(Received 2012.6.23/Revised 1st 2012.8.3, 2nd 2012.9.18/ Accepted 2012.9.26) 